\title{
Representações sociais da Filosofia como disciplina obrigatória num centro de Ensino Médio em Ceilândia, DF
}

\section{Pedro Alves Lopes ${ }^{1}$}

\section{Resumo}

A presente pesquisa levanta concepções, imagens e juízos sobre a Filosofia como disciplina do Ensino Médio, empregando o conceito de "representação social" segundo Serge Moscovici, na perspectiva da psicologia social contemporânea. A pesquisa aponta para as seguintes conclusões: a postura que o professor tem em sala de aula demonstra que não há clareza com relação à especificidade da disciplina Filosofia; os alunos que têm uma atitude participativa descobrem a importância da construção do conhecimento nas aulas; o conhecimento da legislação é importante para que a disciplina Filosofia realize seus objetivos específicos para o Ensino Médio; alunos e professores representam a Filosofia como uma disciplina que contribui positivamente na formação dos indivíduos.

Palavras-chave: Filosofia; Educação; Ensino Médio; Representações sociais.

\section{Resumen}

Esta pesquisa levanta concepciones, imágenes y juicios sobre la Filosofía como disciplina en la Enseñanza Media, empleando el concepto de "representación social" según Serge Moscovici, en la perspectiva de la psicología social contemporánea. La búsqueda apunta hacia las siguientes conclusiones: la actitud del profesor en el aula demuestra que no hay claridad en cuanto a la especificidad de la disciplina Filosofía; los estudiantes que tienen una actitud participativa descubren la importancia de adquirir conocimientos en el aula; conocimiento de la ley es importante para la disciplina Filosofía para lograrlos objetivos específicos de la escuela secundaria; estudiantes y profesores representan la filosofía como una disciplina que contribuye positivamente a la formación de las personas.

Palabras claves: Filosofía. Educación. Enseñanza Media. Representaciones Sociales.

${ }^{1}$ Professor de Filosofia na Educação Básica. 


\section{Introdução}

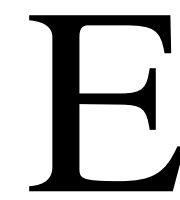

sta pesquisa aborda as percepções e concepções que alunos e professores têm da disciplina Filosofia, procurando analisar como representam sua contribuição, bem como a relação de seu ensino, nas escolas públicas de Nível Médio, com a legislação e os documentos oficiais do governo do Distrito Federal.

A disciplina Filosofia promove indagações no dia a dia de cada um, leva a fazer perguntas e a duvidar das coisas; assim, questionam-se os problemas da vida comum que remetem à origem da vida, das coisas, da política, da paixão, da religião, da arte e do universo.

O ensino de Filosofia envolve a educação política voltada para a participação do sujeito na sociedade, pois o ser humano é determinado, em grande parte pelas relações sociais. Para se falar em compreensão da existência humana e dos fenômenos de um modo geral torna-se necessária a análise crítica. Também é analisada a contribuição da disciplina Filosofia na formação da consciência crítica e na educação para a cidadania.

Da mesma forma como acontece com outros trabalhadores, o professor pode estar sujeito à alienação, no sentido de não dominar nem o processo nem o produto de seu trabalho. Dessa forma, no lugar de ser um educador ativo e criativo, acaba por desenvolver atividades mecânicas, rotinizadas, deixando de fazer o exercício da reflexão-discussão na prática do dia a dia. Esse processo atrapalha o desenvolvimento da consciência crítica, reproduzindo a ideologia que serve às classes dominantes, ou seja, não estabelecendo relação entre os conteúdos historicamente acumulados e a realidade em que o aluno e o professor estão inseridos. O conhecimento só ocorre quando há interação entre professor e aluno; assim, se o professor reproduz seu modo de ver as coisas, o aluno acaba reproduzindo esse modo o que é um ponto importante na pesquisa.

Pode-se dizer que o conhecimento que o professor de Filosofia tem de sua matéria e da metodologia que deve ser utilizada, assim como suas representações sobre sua disciplina, podem aproximá-lo ou afastá-lo das 
ações necessárias ao ensino da disciplina Filosofia tal como proposto nos documentos oficiais.

A representação social é uma forma de conhecimento que tem a função de desenvolver comportamentos e promover a comunicação entre indivíduos. Assim, ao tratar do ensino de Filosofia e da formação dos professores, esta pesquisa busca aumentar o nível de conhecimento dos professores, na esperança de melhorar o ensino dessa disciplina.

Analisar as representações que o professor faz da disciplina Filosofia é importante, considerando o papel que ele tem na relação ensinoaprendizagem; seu trabalho como pode influenciar na construção do conhecimento do aluno. Levando em conta que tudo pode ser objeto de estudo filosófico, é importante pensar não apenas na concepção de Filosofia desse profissional de ensino, mas também nas formas, nos recursos e metodologias com que são trabalhados os conteúdos em sala de aula.

O conhecimento filosófico contribui para desenvolver uma visão mais abrangente do sentido das coisas e da vida, o que leva a pessoa a buscar criticamente o significado de existência humana e o lugar de cada coisa nela. Esta pesquisa busca investigar o papel formador da atitude filosófica, na relação entre professores e alunos, investigando até que ponto ela os leva a elaborar criticamente os conceitos de forma comprometida com a superação da realidade opressora e com a redução do determinismo imposto no dia a dia. Consideramos que tanto a ação quanto a omissão são formas de escolha. Sempre há uma escolha; mesmo quando não se escolhe, se está escolhendo não escolher. O ser humano, pela sua liberdade, pode escolher com mais ou menos interesse, do ponto de vista dos objetivos que ele mesmo se propõe realizar.

Ao tratar do desenvolvimento das aulas ministradas pelos professores e da postura dos alunos ante a Filosofia como disciplina obrigatória do Ensino Médio, esta pesquisa propõe-se ainda a seguinte questão: as representações que alunos e professores fazem dessa disciplina se aproximam do que é proposto nos documentos oficiais do governo, tanto em nível Federal quanto em nível Distrital? 


\section{Contexto da investigação}

O Distrito Federal possui atualmente cerca de 2.852.372 habitantes, segundo censo demográfico do IBGE de 2014, e é dividido em 30 Regiões Administrativas, segundo o Portal do Governo do DF.

A população urbana estimada da Região Administrativa de Ceilândia é de 449.592 habitantes, sendo considerada a mais populosa do Distrito Federal, de acordo com dados da Pesquisa Distrital por Amostra de Domicílios (PDAD) da Companhia de Planejamento (Codeplan), concluída em setembro de 2013.

Nessa RA, em relação à população total, ganha destaque o elevado percentual daqueles que não estudam, que é de 70,66\% dos habitantes. Os que ainda estudam são $29,34 \%$, e destes $23,33 \%$ frequentam a escola pública (Tabela 1). Em relação ao nível de escolaridade, 3,41\% declararam ser analfabetos. Esse percentual, somado ao dos que somente sabem ler e escrever e ao dos que fizeram curso de alfabetização de adultos, chega a $5,58 \%$. A PDAD revela ainda os seguintes dados:

Tabela 1

População, segundo a condição de estudo - Ceilândia, Distrito Federal, 2013

\begin{tabular}{lcc}
\hline Condição de Estudo & No & \% \\
\hline Não estuda & 317.659 & 70,66 \\
Escola Pública & 104.911 & 23,33 \\
Escola Particular & 27.022 & 6,01 \\
\hline \hline \multicolumn{1}{c}{ Total } & $\mathbf{4 4 9 . 5 9 2}$ & $\mathbf{1 0 0 , 0 0}$ \\
\hline \hline
\end{tabular}

Fonte: Codeplan, Pesquisa Distrital por Amostra de Domicílios - Ceilândia, 2013

Na RA de Ceilândia há 89 escolas públicas que integram a SEEDF, sendo 1 Centro Educacional Profissional, 1 Centro Interescolar de Línguas, 2 Centros de Ensino Especial e 12 escolas que atendem o Ensino Médio, sendo 7 Centros de Ensino em que que funciona apenas o Ensino Médio e 5 Centros de Ensino em que que funcionam o Ensino Fundamental e o Médio. No total, o Distrito Federal dispõe de 240 escolas de Ensino Médio. Entre as unidades 
escolares restantes dessa RA, estão escolas que atendem o Ensino Fundamental I, anos iniciais, e Ensino Fundamental II, anos finais.

\section{População e amostra}

Para Sampieri (2010, p. 174), uma população é um conjunto de todos os casos que pertencem a uma mesma especificação.

A presente pesquisa foi realizada no período de agosto a outubro de 2014 em um Centro de Ensino Médio de Ceilândia. A população pesquisada foi de 1.123 alunos. A amostra considerada para efeito da pesquisa são 286 alunos e 2 professores de Filosofia. Trata-se de uma amostra probabilística, pois todos os elementos da população pesquisada têm a mesma possibilidade de serem escolhidos e são obtidos definindo-se as características da população e o tamanho da amostra, e por meio de uma seleção aleatória ou mecânica das unidades de análises (cf. SAMPIERI, 2010, p. 176).

$$
n=\frac{z^{2} \cdot p \cdot q \cdot N}{N E^{2}+z^{2} p \cdot q}
$$

\begin{tabular}{|l|c|c|}
\hline Tamanho da população & N & $\mathbf{1 1 2 3}$ \\
\hline Nível de confiabilidade & Z & 1,96 \\
Variabilidade positiva & P & 0,5 \\
Variabilidade negativa & $\mathbf{Q}$ & 0,5 \\
\hline Precisão ou erro & E & 0,05 \\
\hline Tamanho da amostra & N & $\mathbf{2 8 6}$ \\
\hline
\end{tabular}

A escola é de turno único e oferece lanche aos alunos. Em sua maioria os professores são concursados e, de acordo com a lei, as disciplinas dispõem de professores graduados nas respectivas áreas de atuação. Possuem plano de carreira e sua jornada de trabalho é composta por horas aulas e horas de coordenação pedagógica, essas últimas consideradas como tempo para a 
formação continuada dentro do ambiente escolar e/ou em equipamento próprio da SEEDF.

Por meio de um programa do governo federal, todos os alunos recebem livros didáticos, escolhidos pelos próprios professores da unidade escolar, cada qual em sua respectiva disciplina. As unidades escolares são dotadas de uma supervisão pedagógica e também de coordenação pedagógica, a qual faz a mediação entre as disciplinas, o estudo e a implementação de projetos pedagógicos, assim como a articulação para a elaboração do Projeto Político-Pedagógico. O processo de escolha da gestão escolar realiza-se de forma democrática, com a participação de toda a comunidade escolar.

\section{Estudo de caso}

Para coletar os dados foi utilizado o estudo de caso, que envolveu uma entrevista com os professores, um questionário para alunos e um questionário para um grupo focal com alunos. A entrevista foi feita com 2 professores de Filosofia através de uma guia de dez perguntas. Foram distribuídas em sala de aula as guias com o questionário de alunos com dez perguntas, com explicação do objetivo e o sigilo da pesquisa.

$\mathrm{Na}$ análise de dados foram utilizados métodos de estatística descritiva para organizar, resumir e descrever os aspectos importantes do conjunto de características observadas, comparando tais características entre os conjuntos de dados tabulados. As ferramentas descritivas serão os gráficos e tabelas, e as medidas de síntese foram as porcentagens e médias. A partir dos dados coletados, para a análise qualitativa, foi feita uma análise do discurso como forma de estudo das respostas às questões abertas.

Em concordância com a Resolução no 196/96 do Conselho Nacional de Saúde (CNS) - Ministério da Saúde (BRASIL, 1996), que regulamenta a pesquisa envolvendo seres humanos, foram respeitados os aspectos éticos e legais, de que foram incorporados os três princípios bioéticos: a beneficência, o respeito à dignidade humana (autonomia) e a justiça e equidade. 


\section{Perfil Demográfico da Pesquisa}

- Dos alunos pesquisados, 59,5\% são do sexo feminino, sendo que deste total 47,6\% são alunos do $1^{\circ}$ ano do Ensino Médio, 26,5\% são alunos do $2^{\circ}$ ano e $25,9 \%$ são alunos do $3^{\circ}$ ano.

- Os alunos do sexo masculino são 40,5\% do total e, destes, $48,3 \%$ são alunos do $1^{\circ}$ ano do Ensino Médio, 32,8\% são alunos do $2^{\circ}$ ano e $18,9 \%$ são alunos do $3^{\circ}$ ano.

- No universo de alunos pesquisados (Gráfico 1) 47,9\% são alunos do $1^{\circ}$ ano, $29 \%$ são alunos do $2^{\circ}$ ano e $23,1 \%$ são alunos do $3^{\circ}$ ano.

\section{Gráfico 1}

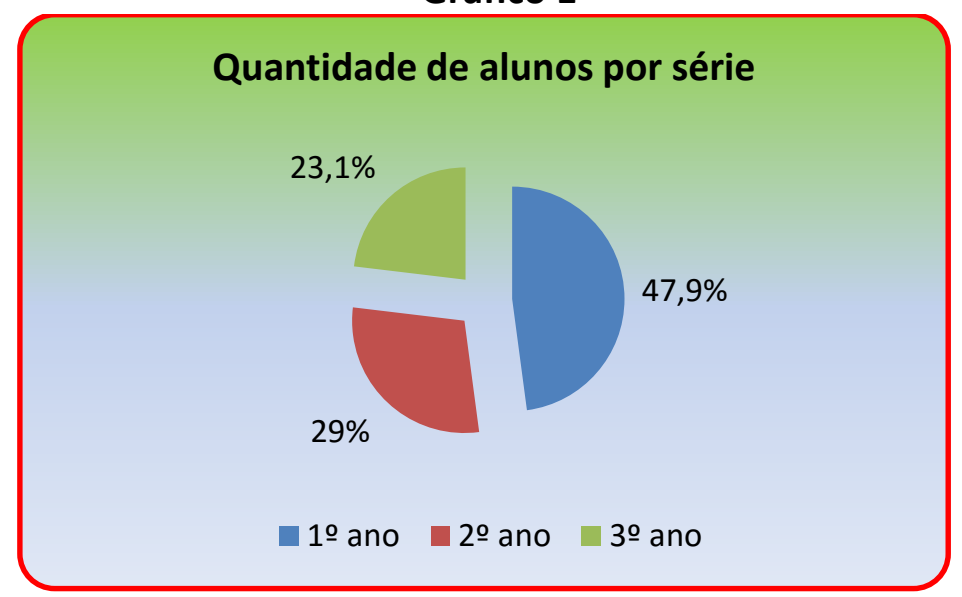

Fonte: elaboração do autor.

- Quanto à faixa etária dos alunos do total da amostra pesquisada (Gráfico 2), 9,4\% têm idade entre 14 e 15 anos, 64\% têm idade entre 16 e 17 anos, 24,1\% têm idade entre 18 e 19 anos e 2,5\% têm idade entre 20 e 21 anos.

- A média de idade dos alunos é de 17,5 anos. 


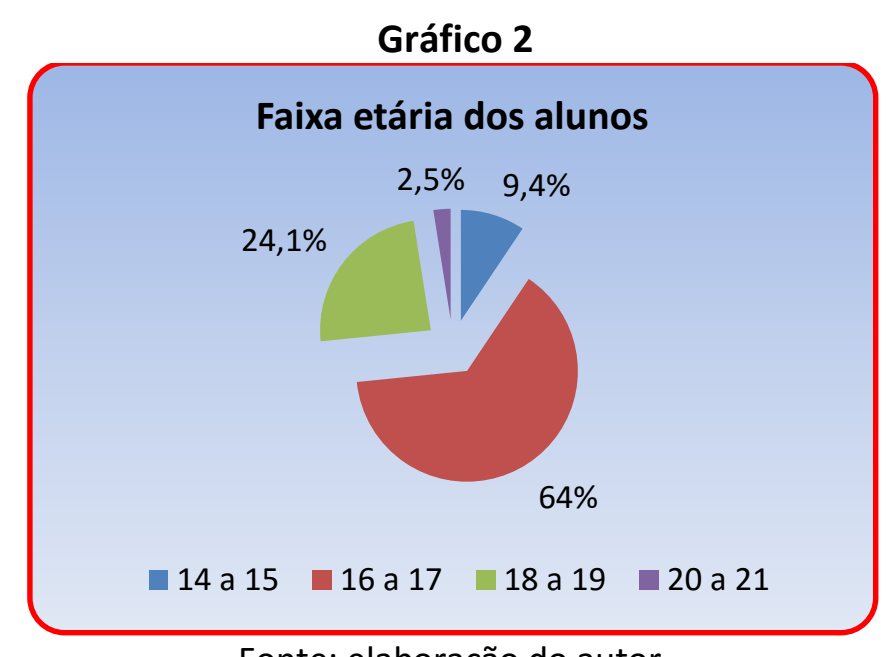

Fonte: elaboração do autor.

- Quanto aos professores, 100\% têm graduação em Filosofia e 100\% têm alguma especialização. Nenhum deles possuía - nem estava cursando - especialização em Filosofia.

A Filosofia como disciplina obrigatória no Ensino Médio

A respeito da questão sobre a Filosofia como disciplina obrigatória no Ensino Médio (Gráfico 3), conforme a Lei $n^{\circ} 11.684 / 2008$, a opinião de 18,2\% dos alunos é de que a presença da Filosofia como disciplina é muito importante; para $47,2 \%$ a Filosofia como disciplina é importante; para 23,4\% ela é uma disciplina pouco importante, e 11,2\% dos alunos são indiferentes à presença da Filosofia como disciplina.

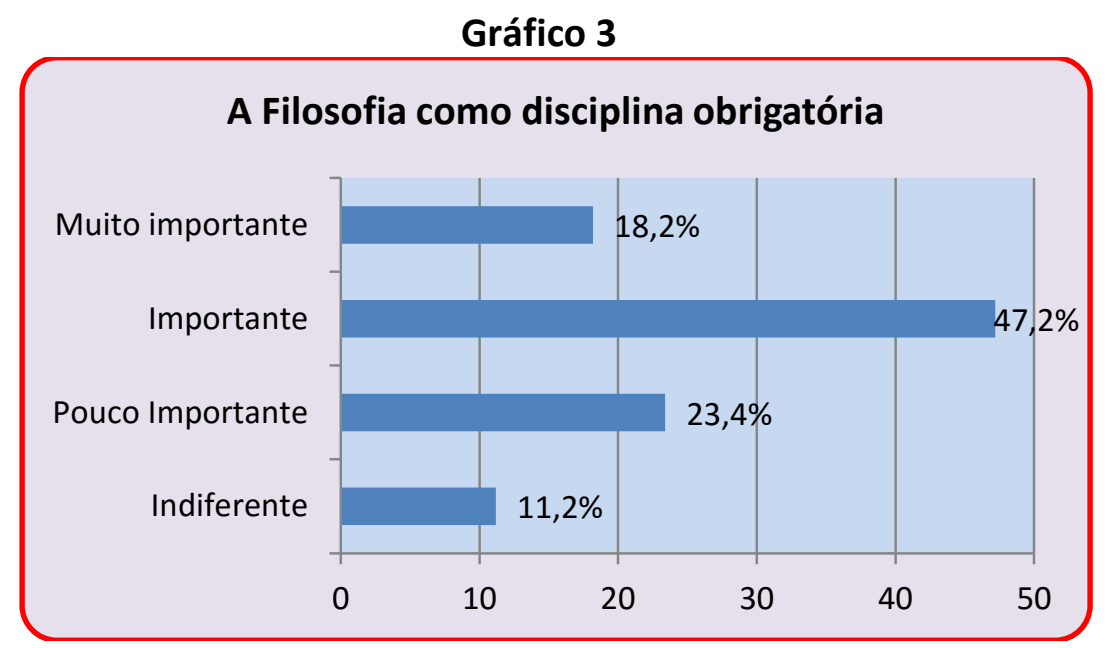

Fonte: elaboração do autor. 
Os alunos que assinalaram a alternativa muito importante responderam que a Filosofia ajuda na formação mental e crítica do indivíduo para questionar o que nos é proposto, contribui para se ter mais conhecimento sobre o que é Filosofia e conhecer os pensadores do passado e do presente, ajudando também a aprender sobre a sociedade e o mundo em que vivemos e sobre a sua formação, além de contribuir para pensar por si mesmo, ter um pensamento próprio.

Os alunos que marcaram a alternativa importante justificaram sua resposta dizendo que a Filosofia reflete sobre a origem da cidadania, serve para questionar algumas coisas da vida no cotidiano, ajuda a entender como as coisas funcionam e como agem umas sobre as outras, ajuda a exercitar a mente reforçando a lógica, desenvolve a arte da crítica, ajuda a entender a própria Filosofia e o pensamento dos filósofos, dialoga sobre a percepção do mundo e ajuda a entender como ele funciona; por ela aprende-se a pensar por conta própria ao ver o mundo de outra forma.

Com relação aos alunos que assinalaram a alternativa pouco importante, eles justificaram que os filósofos têm muitas ideias contraditórias, ela não vai interferir muito na vida, não é uma coisa que se estuda para usar no dia a dia; os alunos têm dificuldade de entender como a disciplina Filosofia é utilizada no cotidiano.

Os alunos que marcaram a alternativa indiferente disseram que a disciplina História é suficiente para estudar as formas de pensamento, e daí concluem que a disciplina Filosofia é confusa, sem sentido, não se aplica à realidade da vida, não vai influenciar na vida profissional no futuro, vai contra a religião, acrescentando a escola precisa de melhores profissionais para lecionar Filosofia.

\section{A disciplina Filosofia e o exercício da cidadania}

Com relação ao ensino de Filosofia e o exercício da cidadania, a pesquisa (Gráfico 4) mostra que na opinião de 26,2\% dos alunos o ensino de Filosofia desperta muito para o exercício da cidadania; para 38,8\% dos alunos a Filosofia desperta em grau médio para a cidadania; para 25,9\% dos alunos o 
ensino de Filosofia ajuda pouco no despertar para o exercício da cidadania e $9,1 \%$ são indiferentes com relação à influência da Filosofia no exercício da cidadania.

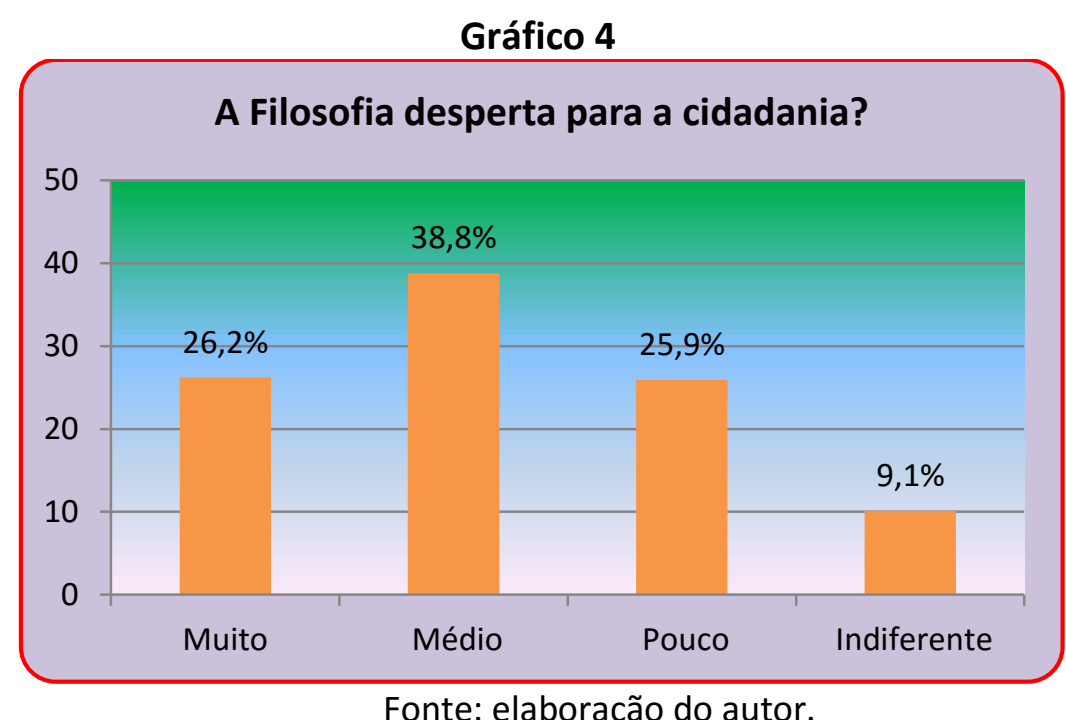

Os alunos que assinalaram a alternativa muito justificaram que a Filosofia prepara o jovem para a vida em sociedade, ajuda a refletir sobre o comportamento humano e a participação como forma de construção da sociedade, faz com que os alunos sejam mais conscientes de suas ações, ensina também a conviver com ideias diferentes, desenvolvendo o senso crítico, combatendo o preconceito e contribuindo para a crítica da situação atual e para a melhora da sociedade.

Os alunos que marcaram a alternativa que aponta para uma influência média do ensino de Filosofia no despertar para o exercício da cidadania, afirmaram que a Filosofia faz refletir sobre a cidadania e leva os alunos a agirem melhor e a aprender a viver em sociedade, ajuda a pensar sobre o cotidiano e promove o diálogo, reflete sobre ética e moral de tal forma que chega a influenciar nas decisões futuras dos estudantes.

Os alunos que assinalaram que a Filosofia ajuda pouco a despertar para a cidadania justificaram dizendo que nas aulas da disciplina só se fala do passado e poucos temas despertam seu interesse, não ajudando a mudar a atitude deles, que não entendem a aula da professora; além disso, há outras 
matérias que tratam do mesmo assunto e são mais importantes, uma vez que a Filosofia não é voltada para a prática social.

Aqueles que são indiferentes justificaram dizendo que o mundo dos pensadores não muda a vida de ninguém, não há relação entre a Filosofia e a sociedade, a Filosofia não é importante e não muda em nada.

\section{A contribuição da disciplina Filosofia para a vida profissional}

Sobre a questão da contribuição da Filosofia para o futuro da vida profissional do aluno, a pesquisa (Gráfico 5) mostra que 19,5\% dos alunos acreditam que a Filosofia contribui muito para o futuro da vida profissional do aluno; 30,7\% consideraram como média essa contribuição; para 28,9\% a Filosofia contribui pouco para o futuro da vida profissional, e 20,9\% são indiferentes com relação à contribuição da disciplina para a vida profissional.

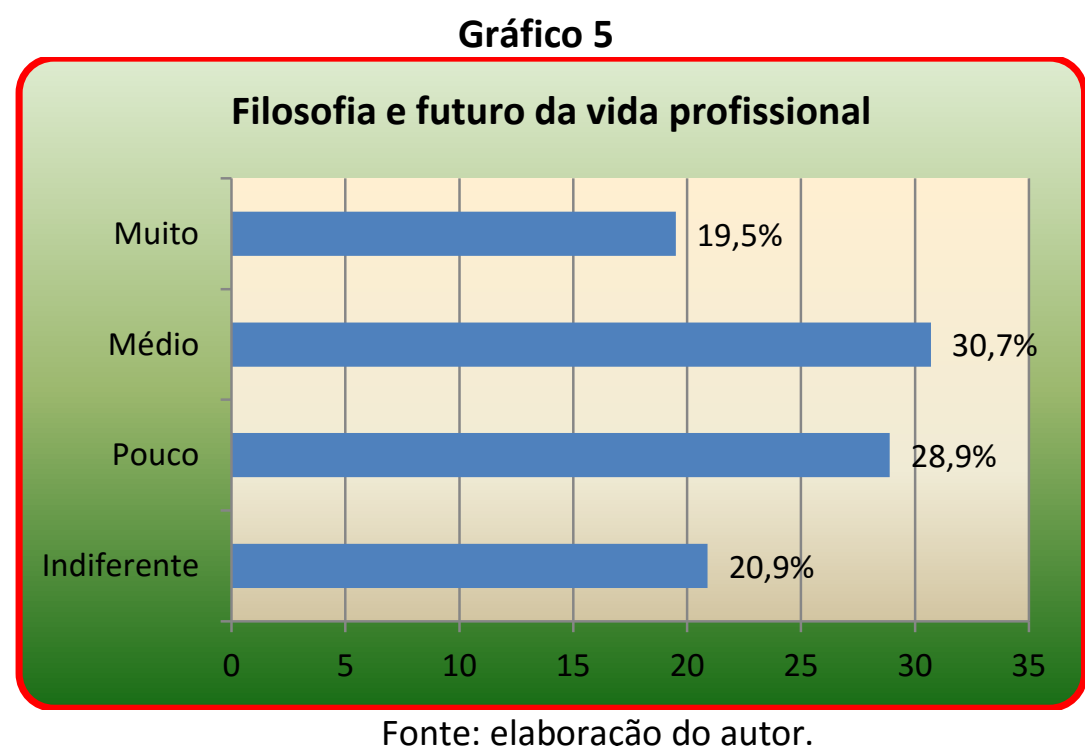

Os alunos que marcaram muito com relação à contribuição da Filosofia disseram que o conhecimento estudado vai ajudar no futuro, e que em alguns cursos superiores a Filosofia é muito importante; a Filosofia ajuda a entender a nós mesmos e a refletir sobre as coisas, assim como para uma melhor convivência com o outro; também ensina a se comportar numa entrevista de emprego. Para alguns alunos, a Filosofia é opção de curso superior e por isso a disciplina contribui muito. 
Os alunos que assinalaram a contribuição média da Filosofia disseram que ela ajuda a refletir sobre as coisas e que despertou para alguns assuntos profissionais; fez ver que o dinheiro não é tão importante quando se trabalha com o que se gosta; também ajuda a conviver em sociedade e assim auxilia profissionalmente, desenvolvendo a capacidade de trabalho em grupo, o que é importante na vida profissional; além disso, ajuda em algumas profissões que têm a ver com Filosofia.

Os alunos que assinalaram que a Filosofia contribui pouco disseram que a Filosofia não influencia no futuro nem na vida de cada um; nem todas as profissões precisam de conhecimento da Filosofia, a única influência é na questão ética e moral.

Os que são indiferentes sobre a influência da Filosofia na vida profissional disseram que a área em que pretendem trabalhar não tem nada a ver com Filosofia, que depois de saírem do Ensino Médio não vão mais usar a Filosofia, acrescentando que as ideias dos filósofos não fazem diferença e não os inspiram na vida profissional.

Como o aluno considera o método que o professor aplica nas aulas Sobre o método que o professor aplica nas aulas (Gráfico 6), 21,7\% dos alunos afirmaram que o professor de Filosofia tem um método ótimo; para $22,7 \%$ o método do professor em sala de aula é muito bom; $41,5 \%$ avaliaram o método como bom, e 14,1\% dos alunos marcaram que o método do professor em sala de aula é ruim.

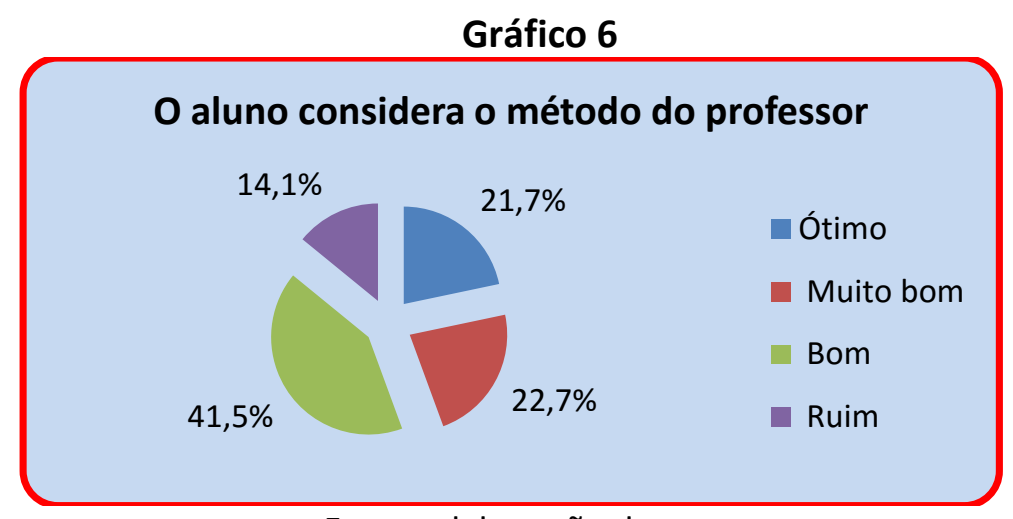

Fonte: elaboração do autor. 
Os alunos que disseram que o método do professor em sala de aula é ótimo justificaram que ela explica bem a matéria e é dinâmica, também interage com os alunos. Através do diálogo e de vídeos propostos pode-se aprender a criar formas de pensar, promovem-se ótimos debates em sala de aula.

Os que avaliaram o método como muito bom e bom disseram que o professor explica de um modo que fica fácil entender, deixa os alunos exporem as ideias e dúvidas, é bem esforçado, faz de tudo para os alunos aprenderem a matéria e leva os alunos a pensarem sobre os próprios pontos de vista acerca dos temas.

Os alunos que responderam que o método utilizado é ruim disseram que a matéria é muito complicada, e é entediante ficar vendo vídeos; o professor não é muito criativo, deveria dar aulas mais dinâmicas, a forma como explica é confusa, coloca muitas coisas diferentes ao mesmo tempo.

Se pudesse escolher, a disciplina Filosofia seria uma opção?

Considerando a questão sobre a opção de estudar a Filosofia na grade de disciplinas, a pesquisa (Gráfico 7) mostra que 60,7\% dos alunos optariam por estudar a disciplina Filosofia em sua grade curricular e 39\% não optariam por estudar Filosofia como disciplina em sua grade curricular.

\section{Gráfico 7}

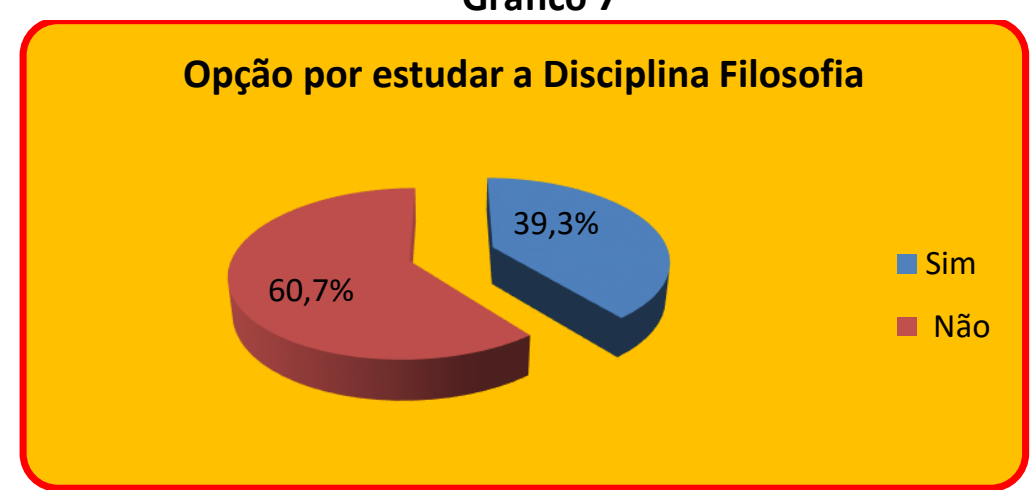

Fonte: elaboração do autor.

Os alunos que responderam sim, disseram que a Filosofia é uma disciplina importante e traz um grande aprendizado e conhecimento, ensina 
valores e a pensar, é importante para entender melhor onde e como vivemos, contribui para aprofundar os vários temas, alguns dos quais estão ligados ao nosso dia a dia, além de ser importante na área de alguns cursos universitários e útil para a convivência das pessoas.

Aqueles que optaram pelo não disseram que não gostam de Filosofia e não têm interesse pela disciplina, acham-na desnecessária e, em sua opinião, há matérias mais importantes para o mercado de trabalho, não vão precisar de Filosofia no futuro, ela não faz parte da vida de cada um e a escola não se interessa em oferecer um bom estudo de Filosofia.

Os temas da disciplina Filosofia e a reflexão crítica

Sobre a questão relativa à relação entre os temas desenvolvidos na disciplina Filosofia e a reflexão crítica, a pesquisa (Gráfico 8) mostra que para 45,6\% dos alunos os temas ajudam muito na reflexão crítica; 29,3\% dos alunos avaliam como média a ajuda da disciplina na reflexão crítica; para 15,9\% dos alunos essa ajuda é pouca, e 9,2\% dos alunos são indiferentes sobre essa contribuição.

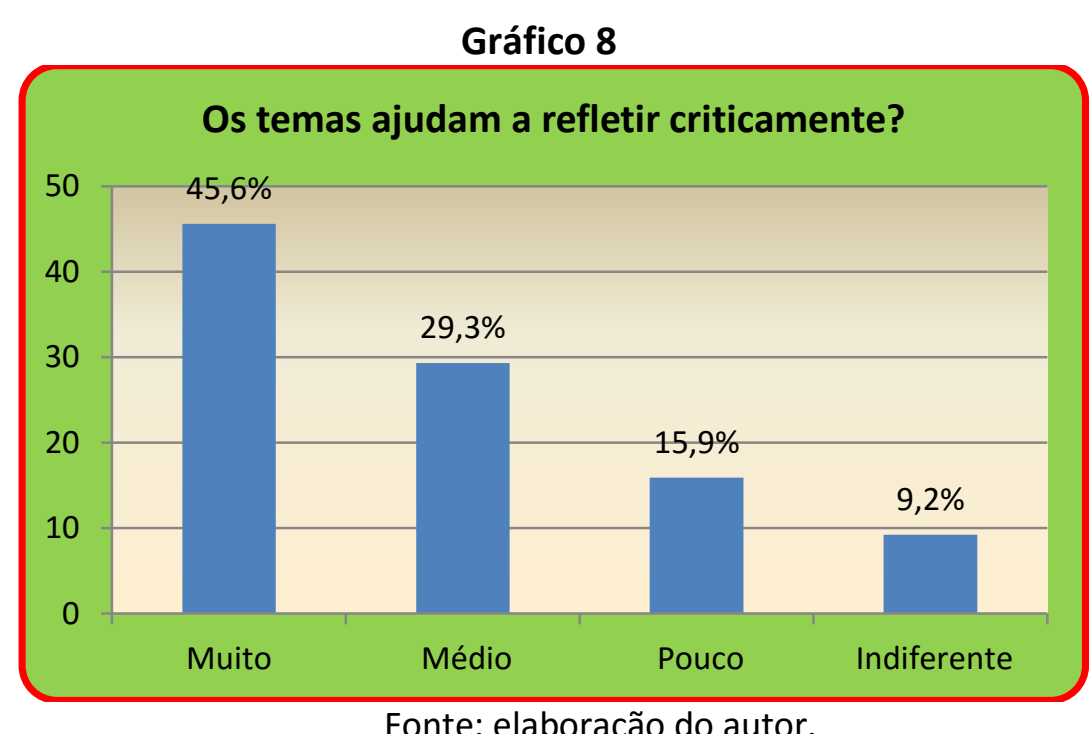

Os alunos que responderam que os temas ajudam muito e em grau médio a refletir criticamente disseram que a disciplina apresenta várias formas de pensar o mundo, a natureza e o universo, levando a refletir sobre a vida e 
o futuro de cada um; a Filosofia está presente em todas as áreas da vida e ajuda a formar a própria opinião, despertando o senso crítico; proporciona conhecimento para discutir sobre diversos assuntos e faz pensar criticamente sobre tudo à nossa volta segundo os grandes filósofos.

Aqueles que responderam que esses temas ajudam pouco na reflexão crítica ou são indiferentes disseram que a Filosofia não muda a realidade, quase ninguém presta atenção na aula, não faz diferença na vida de cada um, é desnecessária.

\section{Resultados da entrevista com o professor}

As duas professoras entrevistadas declararam ter licenciatura em Filosofia. Ambas possuem Especialização (lato sensu), mas nenhuma delas em Filosofia; buscaram outras áreas para se especializarem, como Sociologia e Educação.

As duas professoras consideram importante a Filosofia como disciplina no Ensino Médio, mas as justificativas para essa importância foram diferentes. A professora 1 respondeu que a importância da Filosofia como disciplina estava na sua contribuição para "compreender a si mesmo e como as coisas se organizam" e para responder "por que as coisas são assim?”; já a professora 2 justificou que a Filosofia é importante como disciplina para "pensar antes de agir e aprender valores para a convivência social".

A professora 1 afirmou que a Filosofia como disciplina representa a "possibilidade de ampliação e significação do conhecimento", assim como "a compreensão do todo". A professora 2 disse que a Filosofia como disciplina obrigatória representa "o aprendizado de uma participação consciente na política e desenvolve a visão crítica da mídia".

A professora 1 disse que a contribuição do professor de Filosofia no Ensino Médio para a formação dos alunos está em sua postura em sala de aula, em seu caso como mulher, negra, ceilandense e cidadã. Da mesma forma, a professora 2 falou da importância da postura ética do professor, no sentido de que as palavras que ela pronuncia são um modelo. 
A respeito da postura dos alunos em sala de aula, a professora 1 disse que o "bloqueio do aluno com relação à Filosofia vai sendo vencido ao longo do ano e da maturidade que cada um vai adquirindo, através do tempo e do contato com outras formas de conhecimento". Já a professora 2 achou difícil enfrentar a postura negativa dos alunos com relação à Filosofia e se vê impotente diante dessa situação.

Sobre a questão da contribuição da Filosofia para a vida pessoal e profissional do aluno, as duas professoras acreditam que sim, há uma contribuição nesse sentido. A professora 1 defendeu que a Filosofia ajuda o aluno a se entender, a saber quem ele é. Para ela a Filosofia é questionadora da existência, busca a razão de ser das coisas e ensina a duvidar de tudo, o que é importante. Já a professora 2 disse que a Filosofia leva o aluno a criticar o mundo dado, a questionar a violência, e ensina a ver as coisas não apenas como algo dado, mas como algo que foi construído pelo ser humano.

Sobre a postura do professor em sala de aula diante dos alunos, a professora 1 disse que se posiciona com autoridade e não de forma autoritária, ajuda os alunos a construir a ideia de autoridade como algo necessário. A professora 2 defendeu que a sala de aula é um ambiente de respeito, ambiente democrático, participativo, no qual deve haver reciprocidade.

A relação da Filosofia com outras disciplinas, para a professora 1, é pequena, dando-se apenas com História; não se relaciona com as áreas de Exatas - a relação é buscada, mas não foi possível ainda efetivar. A professora 2 disse que essa relação é complicada, difícil, e não perceptível.

A respeito da questão sobre como a Filosofia deve ser abordada, a professora 1 respondeu que propõe vídeos, pesquisas, produção textual, leitura do livro didático, textos da internet (atualidades), revistas atuais, e procura relacionar os temas com os filósofos. A professora 2 aplica a teoria contextualizada na realidade do aluno, através de filmes, reportagens e documentos.

A professora 1, na questão sobre a contribuição da Filosofia para o projeto de vida do aluno, disse que ensina a ideia de que o outro é necessário à convivência e à harmonia social. A professora 2, nessa questão, disse que 
procura desenvolver a crítica, o raciocínio, a conscientização, busca levar o aluno a se perceber dentro da Filosofia, debate temas sobre a sociedade e questões familiares.

Quando indagada sobre o conhecimento das leis, pareceres e documentos que tratam do ensino de Filosofia no Ensino Médio, a professora 1 disse que não lê as leis, mas participa de cursos oferecidos pela SEEDF. Em resposta a essa questão, a professora 2 disse que leu o Currículo em Movimento, o Documento sobre avaliação do DF e o DCNEM atual.

\section{Conclusão}

Ao analisar as respostas das professoras da disciplina Filosofia sobre o processo ensino-aprendizagem, pode-se identificar uma atitude positiva com relação a essa disciplina, uma vez que elas consideraram a Filosofia uma disciplina importante no Ensino Médio. Essa importância está na contribuição para compreender melhor a si mesmo e como as coisas se organizam. Também disseram que a disciplina ajuda os jovens a aprenderem valores para a convivência social, na medida em que possibilita a aprendizagem de formas conscientes de atuação na política, além de promover a visão crítica das informações transmitidas pela mídia.

No entanto, não se percebe uma clareza com relação à especificidade da Filosofia como disciplina, ou seja, quanto aos objetivos, conteúdos e competências que não seriam alcançados e desenvolvidos satisfatoriamente por outras disciplinas. Identificam-se representações que abarcam objetivos que poderiam ser trabalhados pela educação como um todo, e não apenas pela disciplina Filosofia, quando o documento Currículo em Movimento da Educação Básica - Ensino Médio, da SEEDF, preconiza que é imprescindível a utilização de um mínimo de referências a partir dos textos da tradição filosófica, ainda que seu uso não seja exclusivo.

A formação continuada de professores é importante no desenvolvimento de informações que contribuam na organização do conhecimento que cada professor desenvolve no seu trabalho pedagógico, em sua disciplina. A probabilidade de um professor de Filosofia, com maior 
conhecimento das leis e orientações pedagógicas, elaborar representações sociais mais próximas do real aumenta quando sua formação acadêmica é em Filosofia e possui uma Especialização nessa mesma área.

Com relação ao comportamento e à participação dos alunos nas aulas da disciplina Filosofia pode-se concluir que aqueles que participam das aulas se envolvem nos debates e aprendem a importância da participação como forma de construção coletiva do conhecimento e a conviver com a pluralidade de ideias, respeitando-as. O documento Currículo em Movimento, ao se referir ao objetivo das Ciências Humanas, diz que os assuntos tratados podem explorar condições para uma participação autônoma e ética na vida civil, na busca de uma sociedade cada vez melhor.

Segundo os alunos, a disciplina de Filosofia contribui para a formação da consciência crítica do indivíduo e o pensar por si mesmo, ajudando a aprender sobre a sociedade e a formação do mundo em que se vive: os filósofos fazem pensar nas questões lógicas e o estudo deles ajuda a construir o próprio pensamento, desenvolvendo o raciocínio crítico e educando para a cidadania. Essas percepções aproximam o ensino de Filosofia, no caso estudado, do que dispõem o artigo $2^{\circ}$ da LDB/96 (de acordo com o qual o objetivo da educação consiste no "pleno desenvolvimento do educando, seu preparo para o exercício da cidadania e sua qualificação para o trabalho") e o Currículo em Movimento (que atribui ao ensino na área das Ciências Humanas a função de contribuir para a constituição da identidade pessoal e cultural e para o exercício da cidadania, traduzindo o conhecimento em consciência crítica e criativa, principalmente no que se refere à formação de um protagonismo social e responsável).

\section{Referências}

BRASIL. MEC. Secretaria de Educação Média e Tecnológica. Parâmetros Curriculares Nacionais Ensino Médio: ciências humanas e suas tecnologias. Brasília: Ministério da Educação, 1999. 
. MEC. Conselho Nacional de Saúde. Resolução no 196 de 10 de outubro de 1996. Disponível em:

<conselho.saude.gov.br/docs/Reso196.doc>. Acesso em: 03 nov. 2014.

. MEC. Secretaria de Educação Básica. Orientações curriculares para o ensino médio: Ciências Humanas e suas Tecnologias. Brasília, DF: MEC/SEB, 2006. (Volume 3).

DISTRITO FEDERAL. SE. Currículo em Movimento da Educação Básica Pressupostos Teóricos. Brasília: SEDF, 2014a.

. SE. Currículo em Movimento da Educação Básica - Ensino Médio. Brasília: SEDF, 2014b.

PORTAL DO DISTRITO FEDERAL. < http://www.df.gov.br/sobreo-governo/administracoes-regionais.html>. Acesso em 19 Set. 2014.

INSTITUTO BRASILEIRO DE GEOGRAFIA E ESTATÍSTICA. 2014. Disponível em:

$<$ http://www.ibge.gov.br/estadosat/perfil.php?sigla=df $>$. Acesso em: 19 Set. 2014.

MOSCOVICI, Serge. A representação social da psicanálise. Trad. Álvaro Cabral. Rio de Janeiro: Zahar, 1978.

. Representações sociais: investigações em psicologia social. Trad. Pedrinho Guareschi. Petrópolis: Vozes, 2003.

SAMPIERI, Roberto Hernández; COLLADO, Carlos Fernández; LUCIO, María del Pilar Baptista. Metodologia de la Investigación. 5.ed. México: McGrawHill, 2010. 